\title{
AN ANALYSIS OF 500 HERNIAE ADMITTED TO A GENERAL HOSPITAL
}

\author{
By F. Husain, M.B., B.S., (O.S.M.) \\ Senior House Officer, Orthopaedic Department, Hackney Hospital; late Senior Casualty Officer and S.H.O. to \\ Plastic Unit, Hackney Hospital; late House Surgeon, Royal London Homoeopathic Hospital
}

In this paper it is my purpose to analyse the different factors in 518 patients with herniae who sought operation at the Royal London Homoeopathic Hospital during the years 1938-1955.

\section{Inguinal Herniae}

There were 429 inguinal herniae.

Varieties: Indirect 400, 93 per cent. Direct 29, 7 per cent. Unilateral 406, 95 per cent. Bilateral 23, 5 per cent.

Side: Right, 279; left, 150; thus the rightsided preponderance was almost $2: \mathbf{I}$.

Sex: Male, 329; female, 150 ; the male preponderance was $3: \mathrm{I}$.

Age: The oldest in this series was aged 88 years. The youngest was aged I I months, the average age being 44 years. The age groups were as follows: $0-20$ years $\quad \ldots \quad \ldots \quad 59$ cases, 13.7 per cent. 21-30 $, \quad \ldots \quad \ldots \quad 35 \quad, \quad 8.2 \quad, \quad$,

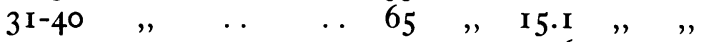
$4 \mathrm{I}-50 \quad, \quad \ldots \quad \ldots 93 \quad, \quad 2 \mathrm{I} .6 \quad, \quad$,

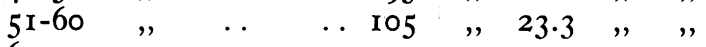
6 I-70 $, \quad \ldots \quad \ldots+49 \quad, \quad$ II.4,$"$,

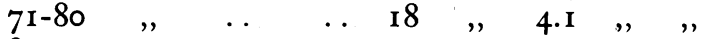
8I-90 ", . $\quad \ldots \quad 5$, I.I ", , Under 50 years of age: Male, 190 cases; female, 60 cases (250).

Over 50 years of age: Male, I39 cases; female, 40 cases (I79).

The above figures tend to show that age plays a part in many cases. The highest incidence of inguinal herniae noted was between the ages of 50 and 60 years.

The right-sided herniae preponderance can perhaps be explained by the fact the right leg is more used for heavy work than the left in the same manner as most people are right-handed.
The male preponderance may be mostly due to the heavier occupation in industry and to the larger internal and external abdominal rings.

\section{Femoral Herniae}

Femoral herniae: total 56 .

Side: Right 33, 59 per cent.; left 23, 4I per cent.; right-sided preponderance, $3: 2$.

Sex: Male, II; female, 45 ; female pree ponderance, $4: \mathrm{I}$.

Age: Oldest patient in this series was aged 77 years. Youngest patient in the series was aged 23 years. Average age 50 years.

$0-21$ years .. .. Nil

2I-30 " . . . . 3 cases, 5.5 per cent.

$\begin{array}{llllllll}3 \mathrm{I}-40 & \quad & \ldots & \ldots & 7 & , & \mathrm{I} 2.5 & ,\end{array}$

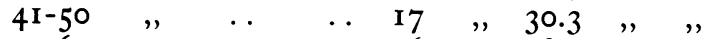

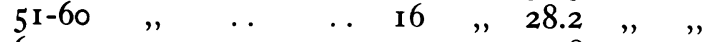

6I-70 ", .

$7 \mathrm{I}-8 \mathrm{O} \quad, \quad \ldots \quad \ldots \quad 3 \quad, \quad 5.5 \quad,$,

Under 50 years of age: Male, 6 cases; female, 23 cases.

Over 50 years of age: Male, 4 cases; female, 23 cases.

\section{Umbilical Herniae}

Sex: Male, I2; female, 2I; female preponderance, $19: \mathrm{I}$.

Age: Oldest patient in the series was aged 72 years. Youngest patient in the series was aged I3 months.

It is noted that femoral herniae and umbilical herniae are commoner in female than male.

Note also that inguinal herniae are much commoner than femoral in both sexes.

I wish to express my gratitude to $\mathrm{Mr}$. Harold Dodd for his encouragement and guidance in the preparation of this paper. 